\title{
Governabilidade e concentração de poder institucional - o Governo FHC
}

\author{
ARGELINA CHEIBUB FIGUEIREDO - FERNANDO LIMONGI
}

\author{
ANA LUZIA VALENTE
}

\begin{abstract}
RESUMO: O artigo analisa o governo Fernando Henrique Cardoso como parte de um padrão mais geral de relações Executivo-Legislativo que se caracteriza por forte concentração de poder nas mãos do Presidente da República e dos líderes partidários. A centralização decisória que se observa nesse governo tem bases institucionais, distinguindo-se do chamado "presidencialismo imperial", de base personalista. Os poderes institucionais de agenda e o controle sobre o processo legislativo têm forte impacto na produção legal e na capacidade do governo em obter apoio para a sua agenda legislativa.
\end{abstract}

\section{Introdução}

o governo Fernando Henrique Cardoso testemunhamos o pleno funcionamento de um sistema decisório que se caracteriza por forte concentração de poder nas mãos do Presidente da República e dos líderes partidários no Congresso. A centralização decisória observada nesse governo é parte de um padrão mais geral de interação ExecutivoLegislativo que resulta da escolha institucional de constituintes e parlamentares $^{1}$. Os extensos poderes legislativos do Executivo, constitucionalmente conferidos, e a alocação de direitos e recursos parlamentares em favor dos líderes partidários, garantida regimentalmente, criaram um modelo institucional que favorece a governabilidade, entendida, em sentido restrito, como a capacidade de fazer valer a agenda legislativa do Executivo.
UNITERMOS: governabilidade, relações ExecutivoLegislativo, produção legal, apoio partidário, agenda legislativa, governo FHC.
Professora do Departamento de Ciência Política do IFCH - Unicamp

Professor do Departamento de Ciência Política da FFLCH - USP

Bolsista de Iniciação Científica da Fapesp e Estagiária do Cebrap 
* Agradecemos o apoio da Fapesp para o Projeto Temático "Instituições Políticas, Padrões de Interação Executivo-Legislativo e Capacidade Governativa" e do CNPq para as bolsas de pesquisa.

Para uma análise detalhada, cf. Figueiredo e Limongi (1999).

Análise recente desse sistema encontra-se em Huber (1996). Na Itália, a medida provisória, instituída em 1948, não fez parte de um conjunto mais amplo de prerrogativas de controle do processo legislativo, que funcionava de forma descentralizada.
A assimetria de poderes entre Executivo e Legislativo, em favor do primeiro, se apóia, portanto, em uma construção institucional. Dessa forma, se distingue marcadamente do chamado "presidencialismo imperial", de base personalista, visto como peculiaridade dos sistemas políticos latino americanos. Desenhos institucionais similares, de fato, se difundiram nas novas democracias contemporâneas da América Latina, do Leste e do Sul da Europa (cf. Carey \& Shugart, 1998). Historicamente, porém, o fenômeno é mais geral, e pode ser observado também nas democracias européias do pós-guerra, especialmente, na França, cujo arcabouço institucional se mantém intacto desde $1958^{2}$.

Como parte desse padrão mais geral, o governo Fernando Henrique Cardoso foi dotado de alta capacidade decisória. O sistema institucional em que se apoiava garantia a dominância do Executivo na produção legal e um alto grau de sucesso na aprovação de sua agenda legislativa.

A agenda legislativa desse governo foi extensa e complexa. Certamente não contemplava o amplo leque de questões que compunham a agenda pública. A questão da desigualdade social, por exemplo, não fazia parte dessa agenda. A estabilidade monetária obteve prioridade máxima, assim como as reformas tidas como necessárias para garantir o controle inflacionário e permitir a inserção do país na economia internacional. A agenda reformista, já esboçada no governo Sarney e reforçada no governo Collor, só então se concretiza em um conjunto abrangente de propostas legislativas. A implementação das reformas, porém, requeria a aprovação de mudanças constitucionais. Para a aprovação de mudanças no texto constitucional, o governo não tinha à sua disposição o aparato institucional que garantia o seu sucesso na implementação da agenda legislativa ordinária. Pelo contrário, por sua natureza constitucional, essas propostas deviam ser submetidas a um processo decisório, cujas regras impunham maiores exigências à base parlamentar do governo, ao mesmo tempo que abriam espaço para a atuação mais ativa da oposição. Ainda assim, não se pode dizer que os resultados alcançados foram modestos.

Para a implementação desse programa, a estratégia de formação do governo foi ampliar as bases de apoio parlamentar, reforçando a participação dos partidos da aliança eleitoral e incorporando novos partidos dentro do espectro ideológico de centro direita. Da mesma forma, os partidos assumiram formalmente sua participação no governo. Essa participação aumentou o acesso a recursos, influência e, portanto, o interesse dos partidos no sucesso do governo; garantindo, por outro lado, o seu apoio às suas propostas legislativas. Este apoio, como veremos, foi forte e estável, mas proporcional à participação de cada partido no governo. Constituiu-se, portanto, um governo de coalizão majoritário de centro direita que fez amplo uso do aparato institucional de que dispunha e colocou em funcionamento um "rolo compressor", como a crônica jornalística e a oposição parlamentar passaram a chamar a atuação do governo e de seus líderes na arena parlamentar. Nesse governo, portanto, verificou-se um majoritarismo exacerbado na definição das políticas públicas nacionais.

A existência da estrutura consociativa de organização política, a fragmentação partidária, a ausência de controle partidário na arena eleitoral, em 
suma, toda a base institucional do sistema de representação política, mantida intacta pela Constituição de 1988 que, além disso, reforçou o federalismo, não impediram a aprovação de emendas constitucionais que compreendiam medidas altamente impopulares e impunham perdas a camadas consideráveis da população, assim como a grupos sociais altamente organizados. Da mesma forma, a despeito do alegado peso dos estados e municípios no Congresso, o governo conseguiu também a recomposição das receitas da União. Por fim, o controle inflacionário foi implementado por meio de uma política de ajuste que logrou efetuar cortes significativos de despesas, ainda que com resultados aquém do que o governo almejava ou via como necessário; e de medidas recessivas com perversos efeitos sociais, que passaram pela aprovação legislativa.

O que se pretende ressaltar aqui, é que tudo isto foi obtido sem que se recorresse a medidas de natureza extra ou para constitucional e legal, a despeito de controvérsias sobre o uso abusivo desses poderes. $\mathrm{O}$ modelo institucional que concentra poderes nas mãos do presidente e das lideranças partidárias, e a conseqüente centralização do processo decisório, restringe os direitos dos parlamentares, funcionando como um freio ao processamento de demandas que, por meio do sistema de representação vigente, são de fato canalizadas para o interior do Congresso Nacional.

Isto não significa dizer que os parlamentares são inteiramente alijados das decisões, nem que o Executivo possa impor sua vontade contra a da maioria do Congresso. Os poderes de agenda do Executivo podem funcionar também como instrumentos para a resolução da "barganha horizontal" entre o governo e sua maioria de apoio, especialmente em governos de coalizão, e não apenas para a resolução do "conflito vertical" entre o governo e o Congresso. Sendo assim, a medida provisória, por exemplo, mais do que uma arma de governos minoritários contra o Congresso, pode ser um poderoso instrumento nas mãos de um governo majoritário: protege a sua maioria contra incentivos para perseguir ganhos particularistas e de curto prazo e facilita a preservação de acordos sobre políticas públicas. O governo FHC é um caso exemplar do uso desse instrumento para a manutenção de um grau razoável de coesão de sua base parlamentar para apoiar medidas que são de difícil aprovação em qualquer sistema democrático.

No governo FHC consolidou-se, portanto, um padrão decisório, em que instrumentos institucionais de controle de agenda facilitaram a atuação concentrada do Executivo e dos líderes dos partidos que faziam parte da coalizão de governo, ampliando enormemente a área de atuação autônoma do Estado e de sua burocracia. Este padrão teve efeitos negativos para o papel do Congresso.

A sua influência direta e autônoma na formulação de políticas públicas diminuiu, especialmente na área econômica. O Congresso deixou de ser o locus decisório e de debates, dando lugar a negociações entre líderes governistas e ministros e técnicos da alta burocracia governamental. Com isto, perdeu capacidade deliberativa, estreitando o espaço de debate público, reduzindo a visibilidade das decisões políticas e o acesso dos cidadãos a informações sobre políticas públicas. Em conseqüência, verifica-se uma diminuição na capacidade do Congresso, enquanto contrapeso institucional e mecanismo de 
controle das ações do Estado, com efeitos sobre a própria possibilidade de controle vertical por parte dos cidadãos.

No entanto, o Congresso desempenhou um importante papel na formulação de políticas sociais. A sua atuação nessa área pautou-se pela preocupação em garantire ampliar direitos universais de cidadania, dando origem a uma extensa legislação sobre meio ambiente, direitos do consumidor, acesso à justiça, garantia de direitos civis e punição de práticas discriminatórias. Não exerceu de forma sistemática e centralizada o seu papel de fiscalização das ações do executivo, mas estabeleceu e aperfeiçoou um sistema de normas e procedimentos regulamentando a ação civil pública e a defesa de direitos coletivos que possibilita o aumento do controle descentralizado de grupos e movimentos sociais e dos cidadãos sobre as ações do Estado. Nesse sentido, o Congresso contribuiu para diminuir a dissociação entre a agenda pública e a agenda do governo.

As seções que se seguem têm por objetivo apresentar algumas evidências e desenvolver um pouco mais cada um desses pontos.

\section{Mecanismos institucionais e a implementação da agenda legislativa do governo}

O sistema decisório nacional caracteriza-se por um alto grau de delegação de poderes: do Legislativo para o Executivo, de um lado, e no interior do Congresso Nacional, dos parlamentares para as lideranças partidárias.

As regras constitucionais que regulam as relações ExecutivoLegislativo atribuem ao primeiro extensos poderes legislativos que lhe permitem controlar a agenda do Legislativo. O executivo brasileiro tem o monopólio de iniciativa legal em áreas fundamentais de regulação como as referentes a matérias tributárias e orçamentárias, além da administração do aparato do Estado; detém o poder de solicitar urgência para os seus projetos, determinando a sua prioridade e prazo de apreciação; e dispõe ainda do mais poderoso de todos os instrumentos legislativos: a prerrogativa de emitir atos com força imediata de lei, através da edição de medidas provisórias. Através da edição de uma MP, o Executivo altera unilateralmente o status quo, criando um fato consumado que, em certas circunstâncias, torna praticamente impossível a sua rejeição. Modifica a estrutura da escolha parlamentar, pois esta não é feita entre o status quo anterior à sua edição e a MP, mas entre esta última e os efeitos que decorreriam de sua rejeição. Sendo assim, mesmo que o Congresso preferisse o status quo à medida provisória, poderia ser levado a aprová-la. Isto significa que se a mesma proposta tivesse sido apresentada como um projeto de lei ordinária poderia ter sido rejeitada. Dessa forma, por meio da medida provisória, o executivo não só determina a pauta dos trabalhos legislativos, como influi nos seus resultados.

As regras regimentais que distribuem poder no interior do Congresso, por sua vez, favorecem os líderes partidários. O presidente da Mesa e os líderes dos partidos estabelecem a pauta dos trabalhos e detém direitos procedimentais que lhes permitem representar a sua bancada. Por meio dessa prerrogativa, controlam os pedidos de solicitação de votações nominais, de des- 
taques para votação em separado e os pedidos de urgência. Estes últimos são especialmente importantes pois a tramitação em regime de urgência permite que os projetos sejam retirados do âmbito de influência das comissões e restringe a apresentação de emendas no plenário. Os líderes têm ainda a prerrogativa de indicar os membros das comissões e substituí-los a qualquer momento. Por meio desses instrumentos os líderes podem exercer, e de fato têm exercido, controle sobre o processo legislativo e sobre o comportamento do plenário.

Esse conjunto de regras de distribuição de poderes institucionais entre Executivo e Legislativo e no interior do Congresso Nacional deu origem a um sistema decisório altamente centralizado. Seu impacto sobre a capacidade decisória dos governos recentes fica óbvio pela análise da tabela abaixo. O executivo domina a produção legislativa em um patamar alto e obtém alto grau de sucesso para suas propostas legislativas em todos os governos do período recente.

\begin{tabular}{l|c|c|c|c|c}
\hline \multicolumn{1}{c|}{ Governos } & Sarney & Collor & Franco & Cardoso & $\begin{array}{c}\text { Total do } \\
\text { período }\end{array}$ \\
\hline \multicolumn{7}{c}{ Média mensal de leis sancionadas por tipo e origem } \\
\hline Executivo & 15.3 & 12.5 & 14.5 & 13.5 & 13.7 \\
\hline Orçamentárias* & 7.1 & 6.0 & 8.4 & 7.9 & 7.5 \\
\hline Medida Provisória & 5.8 & 2.4 & 2.6 & 2.6 & 3.0 \\
\hline Outras Leis & 2.4 & 4.0 & 3.4 & 2.8 & 3.2 \\
\hline Legislativo & 2.7 & 1.6 & 3.2 & 2.9 & 2.6 \\
\hline $\begin{array}{l}\text { Total (Executivo } \\
\text { e Legislativo) }\end{array}$ & 18.1 & 14.1 & 17.7 & 16.4 & 16.3 \\
\hline \multicolumn{6}{|c|}{ Dominância/Sucesso do Executivo } \\
\hline Dominância** & $85 \%$ & $88 \%$ & $82 \%$ & $82 \%$ & $84 \%$ \\
\hline Sucesso*** & $72 \%$ & $65 \%$ & $72 \%$ & $71 \%$ & $71 \%$ \\
\hline
\end{tabular}

Como se vê, não há variações significativas entre os governos nas taxas de dominância do Executivo: a média mensal de leis de sua iniciativa é 13,7 contra 2,6 do legislativo. Seus poderes constitucionais de agenda lhe garantem essa dominância. O maior número de leis refere-se a matérias orçamentárias, área em que o Executivo tem monopólio de iniciativa. Além das leis relativas ao orçamento anual, as leis orçamentárias incluem pedidos de abertura de créditos suplementares para alterar a alocação de despesas aprovadas na lei orçamentária. Constituem importantes instrumentos de distribuição de recursos e, portanto, de definição de prioridades de políticas públicas. O monopólio de iniciativa que possibilita o uso estratégico do tempo para a apresentação desses pedidos é um efetivo instrumento de pressão e diminui a margem de atuação do legislativo. Em consequiência, no período como um todo, apenas quatro projetos de pedidos de crédito foram rejeitados. Esses projetos de lei tiveram também as mais baixas médias de tempo de tramitação.

A tabela acima mostra ainda que o número de leis que se originaram em medidas provisórias é equivalente ao número de leis que o executivo enviou como projetos de lei ordinária: uma média de 3,0 e 3,2 respectivamen-
1. Produção Legal por Governo: Iniciativa, Dominância e Sucesso do Executivo 1989-1998 Fonte: PRODASEN;

Banco de Dados

Legislativos, Cebrap.

* Além das leis relativas ao orçamento anual, referem-se aos pedidos de abertura de créditos suplementares para alterar despesas aprovadas na lei orçamentária.

**Proporção de leis do

Executivo sobre o total de leis sancionadas.

*** Proporção de projetos de lei do Executivo apresentados e aprovados no mesmo governo. 
2. Medidas provisórias por governo 1989-1998

Fonte: PRODASEN; Banco de Dados Legislativos, Cebrap. *A diferença se deve a MPs que perderam a eficácia e não foram reeditadas $e$ MPs em tramitação.

** Inclui leis de origem do legislativo. te por mês. Como a probabilidade de aprovação de medidas por meio de MPs é muito superior à sua aprovação por meio de instrumentos legislativos ordinários, não surpreende o seu uso extensivo pelo executivo.

Por essa razão, foram o instrumento por excelência da implementação de política econômica, especialmente de planos de estabilização monetária: mais de 50\% em todos os governos, e cerca de 60\% das MPs do governo FHC, referem-se a matérias econômicas. A análise do conteúdo das MPs de natureza social e administrativa mostra ainda que muitas delas consistiam em medidas complementares aos planos implementados. Foram então um poderoso instrumento de aprovação da agenda desses governos, tendo em vista a centralidade que a estabilidade econômica assumiu para todos eles. Neste caso, quanto mais drástica a alteração promovida pela MP, menor a capacidade de rejeição do Congresso. O plano Collor representa um caso exemplar: a MP 168 que tratava do chamado "confisco da poupança" foi aprovada sem alterações pelo Congresso, apesar da enorme resistência gerada.

Porém, o governo FHC inaugurou um novo padrão de relações com o legislativo. Esse novo padrão mostra que as MPs, mais do que um meio para superar resistências do legislativo, podem ser instrumentos ainda mais poderosos nas mãos de um governo majoritário. A tabela abaixo resume os principais indicadores quantitativos que nos permitem comparar os governos Collor e FHC quanto ao uso das MPs e as respostas do Congresso.

\begin{tabular}{l|c|c}
\hline Governos & Collor & Cardoso \\
\hline MPs editadas (média mensal) & 2,9 & 3,3 \\
\hline MPs reeditadas (média mensal) & 2,3 & 51,2 \\
\hline Total (média mensal) & 5,2 & 54,6 \\
\hline$\%$ de projetos do Executivo enviados como MP & 30,3 & 47,6 \\
\hline$\%$ MPs rejeitadas* & 7,9 & - \\
\hline$\%$ MPs modificadas pelo Congresso & 59,6 & 23,0 \\
\hline$\%$ MPs transformadas em lei** & 74,2 & 50,3 \\
\hline
\end{tabular}

Os dados reunidos nessa tabela mostram que os dois governos fizeram extenso uso de medidas provisórias: médias mensais equivalentes de 2,9 e 3,3 respectivamente considerando-se apenas as primeiras edições. Diferem marcadamente, porém, quanto à regularidade de seu uso e o volume de reedições e sua relação com instrumentos legislativos ordinários. Enquanto no governo Collor as MPs concentraram em torno da edição do Plano Collor, no governo FHC distribuíram-se igualmente por todo o período. A proporção de projetos enviados como MP em relação aos projetos iniciados por meio do processo legislativo ordinário aumentou consideravelmente. No governo $\mathrm{FHC} 47,6 \%$ dos projetos do executivo (excluindo os orçamentários) foram enviados ao legislativo como medida provisória, contra 30,3\% no governo Collor. Consolidou-se também, nesse governo, a prática já iniciada com a edição do Plano Real no governo anterior, de reedições de MPs. No governo FHC estas subiram drasticamente: de uma média mensal de duas reedições no governo Collor, para mais de cinqüenta. Ou seja, as MPs passa- 
ram a fazer parte da implementação rotineira de política pública.

Por outro lado, os indicadores acima mostram uma participação muito menos ativa do Congresso na apreciação das MPs. Não houve medidas provisórias rejeitadas e diminuiu consideravelmente a proporção de MPs modificadas pelo Congresso por meio de Projetos de Lei de Conversão, que são alternativas propostas pelo legislativo. No governo Collor 59,6\% das MPs foram convertidas em projetos do legislativo, proporção que caiu para apenas $16 \%$ no governo FHC.

A reedição de MPs merece uma análise mais detida. Concretamente, significa que o legislativo deixou de apreciá-las no prazo constitucionalmente previsto. $\mathrm{O}$ executivo pode evitar que uma MP seja votada, se tem dúvidas sobre a sua aprovação, negando quorum para a sua votação, uma estratégia utilizada com freqüência. Porém, se o Congresso reúne maioria contrária à MP, o executivo não tem meios de impedí-lo de votar e rejeitar uma MP, como aconteceu nos governos Collor e Sarney. Se o Congresso tem essa maioria por que haveria de preferir a reedição contínua de MPs?

Uma interpretação genérica e simplista da inação do Congresso é a de "falta de vontade política", como se não votar fosse determinado exclusivamente pela inércia e, portanto, dispensasse ações concretas que exigissem explicações. Uma explicação, sugerida por Carey e Shugart, atribui a delegação de poderes ao Executivo aos interesses da maioria em perseguir políticas particularistas e de curto prazo, deixando as políticas gerais e de longo prazo a cargo do primeiro. Isto ocorre em sistemas políticos onde, como o brasileiro, funciona o "segredo da ineficiência" que consiste na combinação de poderes legislativos fortes e um congresso eleito em bases clientelistas. Esta interpretação estabelece premissas fortes sobre as motivações dos parlamentares e seus interesses em políticas. Assume também que esses necessariamente estão em conflito com os interesses do executivo. Por essa razão, prevê uma relação conflitiva entre os dois poderes, uma vez que presidentes fortes são encorajados a governar unilateralmente e não têm incentivos para negociar (cf. Carey \& Shugart, 1992, p. 37-38 e p. 165).

As evidências, no entanto, reforçam a interpretação que leva em conta os interesses dos partidos da coalizão em cooperar com o governo. A reedição reiterada contou com a colaboração desses líderes, que controlavam o processo de apreciação de MPs, exercendo influência nas suas alterações. Estas, como mostram os registros oficiais, foram freqüentes nas reedições. Essa participação se fazia por meio da atuação das relatorias que, no período, foram controladas pelos dois principais partidos da coalizão, cabendo ao PFL a maioria delas. As comissões especiais formadas para a apreciação de MPs não chegavam a se reunir e visavam fundamentalmente a indicação do relator. Não funcionaram, portanto, como um órgão de deliberação e decisão. As negociações e os acordos com o executivo eram conduzidos, com grande autonomia, pelo relator da MP. Esse padrão decisório resulta da interação entre poderes decorrentes das prerrogativas institucionais de controle de agenda e do processo legislativo, com poderes políticos que resultam da distribuição de cadeiras no legislativo. $O$ custo de reediçãoé menor tanto para o governo, quanto para os partidos que o apóiam.

A aprovação de boa parte da agenda do governo funcionou, portan- 
to, sob o manto protetor das medidas provisórias e do controle dos líderes sobre o processo de apreciação e votação.

Os freqüentes pedidos de urgência para a tramitação de matérias, por parte dos líderes de bancadas, permitiram que grande parte dos projetos de lei fossem votados sem que as comissões tivesse apresentado um parecer sobre a matéria e o processo de votação. Com isto foi possível neutralizar a influência parlamentar nessa instância decisória, onde esta influência pode ser mais efetiva. Os líderes podem ainda influenciar no resultado dos trabalhos das comissões por meio da prerrogativa de indicar e promover alterações na composição das comissões e nas mudanças de seus membros. Usando dessa prerrogativa, agiram muitas vezes no sentido de trocar um parlamentar, cujos vínculos eleitorais tornariam mais difícil seu voto favorável à matéria em questão. Com isto influíam diretamente nos resultados das votações. Este tipo de prática, normalmente vista como manifestação de deformação ou fragilidade dos partidos brasileiros, consistem, na realidade, em uma atuação que visa garantir os interesses do partido como um todo, em detrimento de interesses de parlamentares a partir de seus vínculos eleitorais. Conta, no entanto, com o acordo dos parlamentares que são alvo deste tipo de ação, pois ela "protege" esses vínculos, impedindo que sofram retaliações de suas bases.

A tramitação em urgência aumenta também o controle dos líderes sobre o plenário. Por meio desse instrumento, são capazes de neutralizar também a participação parlamentar em plenário, pois o regime de urgência restringe a apresentação de emendas. A votação em urgência aumenta, também, o controle das lideranças partidárias sobre as informações a respeito da matéria em votação, tornando mais fácil a sua aprovação.

Todavia, tendo em vista a natureza da agenda do governo, a oposição adotou a estratégia de aumentar os custos de aprovação das medidas propostas para a base do governo. Foi considerável o número de projetos levados a votação nominal nesse governo. Como se sabe, a votação nominal de uma matéria depende de solicitação das lideranças partidárias. Tendo em vista a baixa capacidade de influir na pauta e no conteúdo dos projetos legislativos, a oposição atuou no sentido de marcar sua posição política e aumentar a exposição pública das decisões parlamentares, especialmente das medidas impopulares. Para tanto recorreu freqüentemente a pedidos de votação nominal. Cerca de dois terços foram solicitadas pelo PT e PDT. O embate entre líderes oposicionistas e governistas girou muitas vezes em torno da atuação dos primeiros para forçar votações nominais e a dos últimos para impedí-las.

O controle do processo de votaçãoe do plenário pelos líderes governistas adquiriu importância ainda maior na aprovação das reformas constitucionais. Neste caso, o executivo não contava com os poderes legislativos de que dispunha na implementação de suas propostas. Como se sabe, alterações constitucionais requerem condições bastante exigentes para a os seus proponentes: votação nominal para cada alteração proposta e a sua aprovação em dois turnos por três quintos de ambas as casas legislativas. Os seus opositores, por sua vez, contavam com um recurso adicional para a exposição pública das decisões parlamentares: podiam 
solicitar que partes do texto em votação, geralmente as mais impopulares, fossem submetidas a votação em separado. Por meio desse recurso, a mesma matéria era submetida a várias votações. Oresultado foi a ocorrência de um número considerável de votações nominais durante esse governo. A tabela abaixo compara o número de votações nominais ocorridas no governo FHC e nos governos anteriores.

\begin{tabular}{c|c|c|c|c|c|c}
\hline Governo & \multicolumn{3}{|c|}{ Matéria Ordinária } & \multicolumn{3}{c}{ Matéria Constitucional } \\
\hline Objeto & $\begin{array}{c}\text { Procedimento } \\
\mathrm{N}\end{array}$ & $\begin{array}{c}\text { Substantiva } \\
\mathrm{N}\end{array}$ & $\begin{array}{c}\text { Média } \\
\text { Mensal* }\end{array}$ & $\begin{array}{c}\text { Procedimento } \\
\mathrm{N}\end{array}$ & $\begin{array}{c}\text { Substantiva } \\
\mathrm{N}\end{array}$ & $\begin{array}{c}\text { Média } \\
\text { Mensal* }\end{array}$ \\
\hline Outros & 53 & 144 & 2,7 & 2 & 17 & 0,3 \\
\hline FHC & 112 & 115 & 4,7 & 44 & 188 & 4,8 \\
\hline Total & 165 & 259 & 3,5 & 46 & 205 & 2,1 \\
\hline
\end{tabular}

A base parlamentar do governo foi, portanto, freqüentemente posta à prova. Ao todo foram quase 500 votações nominais que correspondem a $75 \%$ das votações do período pós-constituinte. Como se vê pela tabela acima, em média, 3,5 votações de matérias ordinárias e 2,1 de matérias constitucionais foram votadas mensalmente na Câmara de Deputados.

\section{Composição política do governo e apoio parlamentar}

De uma maneira geral, supõe-se que a lógica de formação de governos nos sistemas parlamentaristas e presidencialistas são diametralmente diversas $^{3}$. A prerrogativa do presidente na escolha do ministério é geralmente levada às últimas conseqüências, como se esta escolha não sofresse nenhum constrangimento. Assume-se que a independência do mandato popular do presidente o levaria a superestimar o seu poder e relutar em ceder poder a outros partidos que poderiam compor uma coalizão governamental. Estes, por sua vez, teriam como estratégia dominante fazer oposição ao governo visando conquistar a presidência na eleição seguinte. Supõe-se, portanto, que a participação no governo não gera retornos eleitorais ${ }^{4}$. Assume-se assim, ainda que contra as evidências empíricas, que governos de coalizão são inviáveis no presidencialismo ${ }^{5}$.

Contrariando essas premissas, a formação do ministério FHC obedeceu a estratégias opostas. Apesar da importância que o sucesso do plano real teve na vitória eleitoral, a formação do ministério visava reforçar a aliança eleitoral (PSDB, PFL e PTB) de apoio ao candidato à presidência e ampliar a coalizão governamental com a incorporação de dois partidos do espectro centro-direita: o PMDB, logo no início do governo, e o PPB, no ano seguinte. O governo de ampla coalizão de centro direita constituiu assim uma supermaioria parlamentar que servisse de apoio às reformas constitucionais ${ }^{6}$.

A análise da distribuição dos ministérios e do comportamento dos partidos nas votações nominais ocorridas durante o governo FHC mostra que o apoio parlamentar obtido foi, em geral, alto e proporcional à participação dos partidos no governo.

A distribuição numérica de ministérios não foi estritamente proporcional à força parlamentar dos partidos da coalizão governamental, como
3. Votações nominais na Câmara dos Deputados 1989-1999*

Fonte: Diário do Congresso Nacional; Banco de Dados Legislativos, Cebrap. *Até fevereiro de 1999, final da legislatura correspondente ao primeiro governo FHC.

Para argumentos contrários a essa visão cf. Figueiredo e Limongi (no prelo). Laver e Schofield (1990) mostram que governos multiparidários no parlamentarismo enfrentam problemas similares aos normalmente identificados como peculiares ao presidencialismo.

${ }^{4}$ Esses argumentos são resumidos por Jones (1995, p. 6).

No caso do Brasil, Octavio Amorim Neto (1995) mostra que dois terços dos governos nos períodos 46-64 e 85-98 constituíram gabinetes de coalizões partidárias; Rachel Meneguello (1998) analisa a participação dos partidos nos governos pós 1985 e seus retornos políticoeleitorais.

6 Essa é uma das razões arroladas por Laver e Schofield para a formação de governos supermajoritários. Gabinetes com supermaiorias são encontrados em 46 dos 218 gabinetes por eles analisados (cf. Laver e Schofield, 1990, p. 82, p. 71). 
4. Distribuição de ministérios, participação nos gastos federais e distribuição de cadeiras no Congresso - 1995 Fontes: Meneguello 1998, p. 197-198; SIAF/ Consultoria de Orçamen-

to e Fiscalização da Câmara dos Deputados;

Banco de Dados Legislativos, Cebrap.

* Dados referentes ao orçamento de 1996, o primeiro do Governo FHC. A distribuição dos gastos dos ministérios é praticamente constante no período 95-98.

** Exclui os ministérios militares mostra a tabela abaixo. A vitória eleitoral em primeiro turno e a importância do sucesso do Plano Real, implementado pelo candidato a presidente como Ministro da Fazenda no governo anterior, garantiu ao PSDB o maior número de postos ministeriais. O ministério, porém, teve uma considerável quota de indicações não partidárias: $39 \%$ do total de postos; proporção próxima à do primeiro ministério do governo Collor (42\%). A quota do presidente e do seu partido, além disso, compreendia os ministérios chave à implementação das prioridades de governo, como os ministérios da Fazenda, Planejamento, Comunicações e Indústria e Comércio, garantindo a ele o controle sobre a condução da política econômica e a orientação geral da política de governo.

\begin{tabular}{l|c|c|c|c|c}
\hline \multicolumn{1}{c|}{ Órgão } & $\begin{array}{c}\text { Número de } \\
\text { Ministérios }\end{array}$ & $\begin{array}{c}\% \\
\text { Ministérios }\end{array}$ & $\begin{array}{c}\% \\
\text { Orçamento } \\
\text { Realizado* }\end{array}$ & $\begin{array}{c}\% \\
\text { Cadeiras } \\
\text { Câmara }\end{array}$ & $\begin{array}{c}\% \\
\text { Cadeiras } \\
\text { Senado }\end{array}$ \\
\hline Titulares sem partido & 7 & 39 & 30 & - & - \\
\hline Titulares do PSDB & 5 & 28 & 13 & 14 & 19 \\
\hline Titulares do PFL & 3 & 17 & 48 & 18 & 22 \\
\hline Titulares do PMDB & 2 & 11 & 5 & 20 & 23 \\
\hline Titular do PTB & 1 & 5 & 4 & 6 & 5 \\
\hline Total geral** & 18 & 100 & 100 & 58 & 69 \\
\hline
\end{tabular}

O número de postos que os partidos detêm, porém, não diz tudo sobre a sua importância e papel na coalizão governamental. Ao principal parceiro da aliança eleitoral, o PFL, além de uma participação proporcional ao seu peso parlamentar, foi garantido o controle da maior fatia dos gastos públicos. Os três ministérios ocupados pelo PFL são responsáveis pela maior participação no orçamento federal. Na realidade, apenas o Ministério da Previdência, por todo o período controlado pelo PFL, é responsável por quase $47 \%$ do total de gastos dos ministérios (excluídos os militares). Os dois outros ministérios ocupados pelo PFL - Minas e Energia e Meio Ambiente - respondem, portanto, por parcela pequena dos gastos governamentais.

A indicação do PTB para o ministério da Agricultura pode ser atribuída ao interesse dos parlamentares desse partido na política para o setor.

Levando em conta ainda interesses dos partidos em áreas específicas de políticas públicas, cabe ressaltar que para um partido como o PFL, dependente de recursos de patronagem, é sem dúvida importante o controle do ministério da Previdência. Porém, o comprometimento de parte desses recursos com despesas legalmente previstas com os benefícios providos diminui consideravelmente o montante de recursos passíveis de uso político. Além disso, há que se levar em conta que o comando do ministério implica, também, compromisso com a implementação da política do governo e que a natureza das mudanças propostas impõe ao seu titular custos na interação com as bases do partido.

O PMDB, partido com maior representação no Congresso, ficou subrepresentado: obteve o menor número de pastas e a menor parcela no orçamento. Além disso, os ministros indicados - Nelson Jobim para a Justiça e Odacir Klein para os Transportes - representavam apenas uma ala do partido. 
De uma maneira geral, o apoio ao governo foi a tônica. A coalizão governamental apoiou unida as propostas legislativas que compunham a agenda do governo. A análise das votações nominais do governo FHC mostra que os líderes dos partidos que faziam parte da coalizão governamental encaminharam votos de acordo com o líder do governo em $91 \%$ das votações que faziam parte da agenda do governo ${ }^{7}$. Em menos de $10 \%$ dos casos, ela se dividiu, seja por discordância ou por liberação da bancada. As bancadas desses partidos acompanharam as indicações de seus líderes, apresentando índices de disciplina médios de $90 \%$. Estas proporções se mantêm constantes para todos os tipos e natureza de votações, inclusive matérias constitucionais.

No entanto, o grau de apoio dos líderes e a disciplina dos partidosmembros da coalizão variaram de acordo com a sua participação no governo. O PMDB e o PPB foram os partidos com mais baixas taxas de disciplina ( $82 \%$ e $84 \%$ respectivamente), enquanto os principais parceiros na coalizão governamental foram responsáveis pelos mais altos índices de apoio: 95\% o PFL e $93 \%$ o PSDB.

Este aspecto nos leva a um último ponto que não pode ser desconsiderado: a proximidade entre a agenda legislativa do governo e as preferências dos parlamentares. Pesquisas de opinião revelam que a distribuição de preferências dos parlamentares os aproxima da agenda reformista, e essas opiniões podem ser identificadas com os partidos de centro direita (cf. Almeida \& Moya, 1997; Kinzo, 1993; Rodrigues, 1995).

A análise do comportamento dos partidos nas votações nominais mostra que o conflito no Congresso se estrutura em bases partidárias e que os partidos podem ser dispostos em um contínuo ideológico no eixo esquerdadireita, contínuo este que coincide com a posição a eles normalmente atribuídas. Ou seja, da esquerda para a direita os sete maiores partidos ocupam as seguintes posições no espaço ideológico: PT, PDT, PSDB, PMDB, PTB, PFLE PPB.

Os encaminhamentos de voto dos líderes partidários revelam o ordenamento da posição ideológica dos partidos: a probabilidade de indicações semelhantes cai monotonicamente à medida que a distância ideológica entre os partidos aumenta. As coalizões de centro direita foram a tônica do período. A comparação entre os diferentes governos, no entanto, mostra que as alianças se alteraram. Cabe mencionar especialmente a aproximação entre PFL e PSDB: enquanto no governo Collor as indicações semelhantes entre esses dois partidos era de 42\%, no governo FHC os líderes dos dois partidos indicaram votos semelhantes em $92 \%$ das votações nominais. A distância entre partidos que compõem a coalizão é um fator chave no funcionamento do governo (cf. Laver \& Schofield, 1990; Tsebelis, 1997).

\section{O Congresso e o governo}

Poderes institucionais de agenda e controle sobre o processo legislativo têm forte impacto na produção legal e na capacidade dos governos em obter apoio para a sua agenda legislativa. Esses poderes afetam a estrutura
As votações definidas como parte da agenda do governo são aquelas sobre as quais o líder do governo na Câmara se manifestou. 
de incentivos dos políticos levando-os a cooperarem entre si e com o governo na elaboração de políticas públicas ${ }^{8}$. Em governos de coalizão poderes institucionais podem ser usados para facilitar e preservar acordos entre o governo e sua maioria e, assim, aumentar a coesão da coalizão de apoio ao governo. Essas prerrogativas, normalmente vistas como traços distintivos do parlamentarismo (cf. Tsebelis, 1997), podem produzir os mesmos efeitos no presidencialismo, como mostra a análise aqui feita do governo FHC.

A centralização do processo decisório reduz a influência dos parlamentares, limitando o acesso a recursos que lhes permitam garantir benefícios para suas clientelas. Dessa forma, elimina a possibilidade de que o Congresso se constitua em veto institucional à agenda governamental em decorrência de divergências de interesses entre os dois poderes. Ou seja, afeta diretamente a fonte onde tem origem o que é normalmente identificado como "crise de governabilidade". Contribui para impedir que o conflito institucional latente, contido no princípio de separação de poderes, se concretize. Em suma, aumenta a governabilidade, entendida como a capacidade do governo em fazer valer a sua agenda.

Pode-se observar, no entanto, como de fato ocorreu ao longo do governo FHC, uma dissociação entre as prioridades da agenda legislativa do governo e questões fundamentais da agenda pública, como o problema das desigualdades sociais. O Congresso é mais sensível a pressões eleitorais, seja de interesses locais ou corporativos, seja de grupos e camadas mais amplas. Por isto, observa-se também uma dissociação entre a agenda legislativa do Executivo e do Legislativo.

A agenda legislativa do Congresso é social, em contraposição à agenda econômica do governo. Apenas nessa área de política pública a participação do Congresso se iguala à do Executivo. A análise do conteúdo das leis de iniciativa do legislativo revela que a grande maioria delas se refere a questões de natureza geral. Portanto, ao contrário do que normalmente se propala, a ação do Congresso não se volta para o atendimento de clientelas específicas: $86 \%$ das leis sociais do legislativo são de natureza geral; criam e ampliam direitos universais ou se aplicam a amplas categorias sociais. As políticas sociais do executivo, como complementares à política econômica, são de natureza restritiva.

O problema da desigualdade e da participação social dominou a agenda pública da redemocratizaçãoe a constituinte deu estatuto constitucional a parte significativa das demandas que se fizeram sentir pela pressão social, tanto de grupos corporativos como de amplas camadas da sociedade. Com o aprofundamento da crise fiscal e as mudanças na economia mundial, o ajuste das contas públicas e as reformas econômicas passaram a dominar a agenda dos diferentes governos, mas só se transformaram em propostas legislativas no governo FHC. Políticas redistributivas não estavam contempladas. A diminuição das desigualdades sociais, na visão do governo, dependia diretamente da resolução dos problemas econômicos e da manutenção da estabilidade. O sucesso eleitoral do Plano Real e seus efeitos imediatos sobre o poder de compra das camadas mais baixas da população garantiram a autonomia do governo na implementação de sua agenda legislativa.

${ }^{8}$ Para o argumento completo cf. Figueiredo e Limongi (no prelo).
$\mathrm{O}$ aprofundamento dos efeitos da crise, no entanto, teve reflexos imediatos no Congresso, aumentando as divergências na base do governo. 
No entanto, ainda que essas pressões tenham repercutido no Congresso, os incentivos do sistema, tendo em vista os interesses dos partidos, vão no sentido da rearticulação da base de apoio ao governo. Dessa forma, o Congresso, ainda que servindo de porta de entrada para essas demandas, têm baixa autonomia na definição da pauta de prioridades de políticas públicas.

O problema da governabilidade tem sido tratado, na literatura nacional, como na internacional, como dependente diretamente da forma de governo e do sistema eleitoral. Por esta razão, as propostas de reformas institucionais enfatizam a importância de instituições restritivas à entrada de demandas no sistema político, tais como, a adoção do parlamentarismo para promover a fusão de poderes e mudanças na legislação partidária visando limitar o número de partidos e o acesso ao legislativo.

Procuramos mostrar que a concentração de poder decisório produz muitos dos efeitos buscados pelos proponentes dessas reformas. O governo brasileiro não se encontra paralisado por falta de apoio partidário e parlamentar. Sendo assim, não há razões para diminuir o número de partidos e, muito menos, conferir maiores vantagens aos líderes partidários. Da mesma forma, está longe de ser verdade que o governo brasileiro se encontra imobilizado porque soterrado por excessivas demandas da sociedade, que se expressam sem filtros no sistema político, em razão da fragilidade institucional dos partidos políticos. Introduzir barreiras de entrada no sistema político poderia restringir ainda mais o papel que o Congresso Nacional exerce sobre a definição da agenda do governo.

Recebido para publicação em setembro/1999

FIGUEIREDO, Argelina C.; LIMONGI, Fernando \& VALENTE, Ana Luiza. Governability and institutional power concentration: the government of FHC. Tempo Social; Rev. Sociol. USP, S. Paulo, 11(2): 49-62, Oct. 1999 (edited Feb. 2000).

ABSTRACT: This article tries to analyses the government of FHC as part of a more general pattern of Executive-Legislative relationship which are featured by a strong concentration of power in the hands of the President and the Party leaders as well. The centralization of the decisions that is noticed in this government has institutional basis, distinguishing itself from the called "imperial presidencialism", with personalistic basis. The institutional power and the control over the legislative process have a strong impact in the legal production and in the capacity of the

UNITERIVS: governability, Executive-Legislative relationship, legal production, party support, legislative agenda, FHC government. government in obtaining the support for his legislative agenda. 


\section{REFERÊNCIASBIBLIOGRÁFICAS}

Almeida, Maria H. \& Moya, Maurício. (1997) Reforma Negociada: o Congresso e a Política de Privatização. Revista Brasileira de Ciências Sociais, São Paulo, 12(34): 119-132.

Amorim Neto, Octavio. (1995) Cabinet formation and party politics in Brazil, Trabalho Apresentado no XIX Congresso da Latin American Studies Association. Atlanta.

Carey, John M. \& Shugart, Mattew S. (1992) Presidents and Assemblies. Cambridge, Cambridge University Press.

. (1998) Executive Decree Authority. Cambridge, Cambridge University Press.

FigueIredo, Argelina C. \& Limongi, Fernando. (1999) Executivo e Legislativo na Nova Ordem Constitucional. Rio de Janeiro, Editora FGV.

Presidential Power, Legislative Organization and Party Behavior in Brazil. Comparative Politics, forthcoming (no prelo).

Huber, John D. (1996) Rationalizing Parliament. Cambridge, Cambridge University Press.

Jones, Mark P. (1995) Electoral laws and the survival of presidential democracies. Notredame, University of Notredame Press.

KInzo, Maria D’Alva Gil. (1993) Radiografia do quadro partidário brasileiro. Fundação Konrad Adenauer-Stifung. Pesquisa no 1, p. 01-122.

LaVer, Michael J. \& SchofIELD, Norman. (1990) Multiparty Government. Cambridge, Cambridge University Press.

Meneguello, Rachel. (1998) Partidos e governo no Brasil contemporâneo. São Paulo, Paz e Terra.

RodRIGUES, Leôncio Martins. (1995) Eleições, fragmentação partidária e governabilidade. Novos Estudos, 41: 78-90, março.

Tsebelis, George. (1997) Processo decisório em sistemas políticos: Veto players no presidencialismo, parlamentarismo, multicameralismo e pluripartidarismo. Revista Brasileira de Ciências Sociais, São Paulo, 12(34): 89-117. 